\title{
Gastrin-Releasing Peptide Receptor Expression in Human Hepatocellular Carcinoma, Cirrhosis and Normal Hepatic Tissue
}

\author{
Lazaretti NS*, Macedo BR, Izetti P, Meurer L, Rodriguez R and Schwartsmann G \\ Cancer Research Laboratory, Hospital de Clínicas de Porto Alegre, Universidade Federal do Rio Grande do Sul, Porto Alegre, Brazil
}

\begin{abstract}
Background: Hepatocellular carcinoma is a malignancy with a poor prognosis, showing a high relapse and mortality rates despite diverse treatment modalities. In this study, we evaluated whether hepatocellular carcinoma, cirrhotic and normal hepatic tissue express the gastrin releasing peptide receptor and whether there is a significant difference in its distribution among neoplastic and non-neoplastic tissue.
\end{abstract}

Methods: Sections of paraffin-embedded hepatocelluar carcinomas and cirrhotic surrounding tissues from 61 patients with primary hepatocellular carcinoma were studied, as well as 22 samples from non-cirrhotic and non-neoplastic hepatic tissue. The relationship of gastrin releasing peptide receptor expression with clinicopathologic parameters and clinical outcome was evaluated.

Results: Gastrin releasing peptide receptor immunoexpression was demonstrated in the parenchymal tumor cells in $77 \%$ of tumor tissue samples (47/61) and was moderately to strongly expressed in $57.4 \%$ of these cases. In the surrounding cirrhotic liver, It immunostaining was also observed, showing a high expression in $15 / 31$ of cases (48.4\%). In the normal hepatic tissue, it was also expressed, mostly with a weak to moderate expression (36.4 and 59.1, respectively). Gastrin releasing peptide receptor expression was significantly associated with tumor stage $(\mathrm{P}=0.047)$, but no correlation was observed with other clinicopathologic parameters.

Conclusion: Given the aberrant gastrin releasing peptide receptor expression found in a different set of samples, including normal liver tissue, it may not to be a so interesting target for potential clinical applications of gastrin releasing peptide receptor antagonists in hepatocellular carcinoma, but more studies with larger samples should be conducted.

\section{Introduction}

Bombesin/gastrin-releasing peptides (BN/GRP) were demonstrated to bind selectively to cell surface receptors, acting as autocrine mitogenic stimuli for the growth of various types of malignancies in culture [1]. BN/GRP receptors are expressed on a wide variety of tumors, including small lung carcinoma, gliomas, pancreatic, prostatic, breast and ovarian cancers $[2,3]$.

Notably, BN/GRP receptor antagonists, such as RC-3095, were shown to produce long-lasting tumor regressions in various in vivo murine and human tumor models carcinomas [4-6]. Following the binding of RC-3095 to BN/GRP receptors, a down-regulation of EGF and VEGF receptors was observed [7].

In our laboratory, we have looked at biopsy specimens obtained from patients with cervical cancer, and a high expression of BN/GRP receptors was observed [8]. In addition, using an in vivo rat glioma model, we were able to demonstrate significant tumor responses with the combined use of temozolamide and RC-3095 [9]. More recently, a high GRPR content was also observed in human glioma samples by our group [10].

Considering its novel mechanism of action, as well as the lack of dose-limiting toxicities of RC- 3095 in animal studies, we have decided to perform a Phase I trial of this agent in patients with advanced and refractory malignancies. An analytical method for the measurement of RC- 3095 in human plasma was also developed by our group [11].
Interestingly, our data confirmed the safety of RC- 3095 in a series of 25 cancer patients, and evidence of antitumor effects was also shown [12].

The present study is part of our effort to identify tumor types that could be suitable for this experimental therapeutic intervention in early Phase II clinical trials. For that purpose, our approach consisted in the evaluation of sizeable series of paraffin biopsy samples obtained from cancer patients with different types of cancers who were treated at our institution. Tumor types exhibiting a high GRPR expression ratio between tumor/normal tissue are potential candidates to be considered for clinical trials with the GRPR antagonists RC-3095.

HCC is the fifth most common cancer worldwide and the most common form of liver cancer, being responsible for $80 \%$ of primary malignant tumors in adults, and frequently occurs in the setting of chronic liver disease and cirrhosis [13]. HCC is highly resistant to the available chemotherapeutic agents, administered either alone or in combination [14], and the median survival following diagnosis ranges from approximately 6 to 20 months [15-17].

${ }^{\star}$ Correspondence to: Nicolas Lazaretti, Rua Uruguai 2001, Sala 811, Bloco B Passo Fundo - RS, Brazil, CEP 99010-112, E-mail: nicolaslazaretti@yahoo.com.br

Key words: hepatocellular carcinoma, gastrin release peptide receptor, cirrhosis, normal hepatic tissue

Received: September 23, 2018; Accepted: November 26, 2018; Published: November 29, 2018 
The available literature on the expression of BN/GRP receptors in HCC is scanty. Some experimental studies indicate that bombesin is present in rat hepatocellular tumors [18,19]. In one study, the occurrence of BN/GRP receptors in human hepatic cancers transplanted in nude mice was reported, and cytotoxic peptide analogs targeted to these receptors inhibit growth of this tumor [20]. In the present study, we describe the BN/GRP receptor expression in a series of paraffin blocs obtained from patients with HCC treated at our institution. We have also investigated whether the expression of GRPR could be a predictor of clinical outcome.

\section{Methods}

A retrospective search in our archives between 2004 and 2009 showed that 87 patients were found to have the diagnosis of HCC, leading to 79 tissue samples identified from the pathology records of the Department of Pathology of our Institution. After pathological review, 61 samples of representative paraffin wax block were processed by immunohistochemical technique and included in the study.

During the pathological review of the cancer tissues, an additional 30 samples of cirrhotic surrounding tissue and 22 samples of nonneoplastic and non-cirrhotic tissue from patients without cancer were selected as controls. Samples of normal tissue were hard to obtain from the same patients considering that a high proportion of cases were provided by incisional biopsy, not being associated with a large amount of tissue available for the study.

Clinical data were available in all $61 \mathrm{HCC}$ cases and patients were followed up after histological diagnosis for a median follow-up time of survival cases of 7 months (range: $1-108$ months; $S D \pm 21.9$ ).

\section{Immunohistochemistry (IHC)}

IHC was performed on formalin-fixed paraffin-embedded samples of HCC tissues held by the Department of Pathology. The blocks were cut into 4-mm-thick sections and mounted on microscope slides. The primary antibody used was a rabbit polyclonal antibody antiGRPR (\#OPA1-15619, Affinity Bioreagents, USA). After dewaxing, inactivating endogenous peroxidase activity and blocking cross-reaction with normal serum, $4 \mu \mathrm{m}$ sections were incubated overnight at $4^{\circ} \mathrm{C}$ with a diluted solution of the primary antibody (1:50). Identification of primary antibody location was achieved by subsequent application of biotinylated antibody, streptavidin horseradish peroxidase conjugate (LSAB, Dako) and diaminobenzidine tetrahydrochloride $/ \mathrm{H}_{2} \mathrm{O}_{2}$ (Kit $\mathrm{DAB}$, DakoStaining).

\section{Assessment of Staining Patterns}

For each antibody, a pathologist scored the staining intensity (0 = no staining; $1 \pm$ weak staining; $2 \pm$ moderate staining; $3 \pm$ strong staining) of tumor areas and adjacent tissue for all the specimens. Specimens in which one or more tumor areas with different staining intensities were present were scored for the most prevalent intensity.

Specimens with focal uptake amidst negative cancer tissue scored 1+. For the purposes of data presentation, GRPR expression was classified as "low" if the sum score of intensity was $\leq+1$ and as "high" if score was between +2 and +3 (moderate to strong staining).

\section{Statistical analysis}

Data were evaluated using SPSS 14.0. Significant differences between GRPR expression among lesions and surrounding tissues were evaluated using KruskalWallis analysis of variance followed by
Mann-Whitney tests. Correlation between GRPR expression and clinicopathologic variables was evaluated using a $\chi^{2}$ test. Kaplan-Meier survival curves were calculated using tumor recurrence (defined as the first appearance of a tumor at any site following definitive treatment) or death as the end points. The difference of overall survival curve or disease-free survival curve was examined by log-rank test. Adequacy of sample size was determined by power analysis. Data are expressed as means $\pm \mathrm{SE}$, unless otherwise specified, with $\mathrm{P}<0.05$ considered significant.

\section{Results}

Sample characteristics are described in Table 1. The mean age at cancer diagnosis was 59.0 years ( $\mathrm{SD}=13.1$; range: $14-83$ years). Among the 61 patients with available clinical information, $55.9 \%$ were stage II or IV disease, $67.2(n=41)$ had cirrhotic liver and $61 \%(n=36 / 59)$ were $\mathrm{HCV}$ positive.

GRPR immunoexpression was demonstrated in the parenchymal tumor cells in $77 \%$ of tumor tissue samples (47/61) $\mathrm{m}$ and was moderately to strongly expressed in $57.4 \%$ of these cases (Figure 1). In adjacent non-cancerous hepatocellular tissue, GRPR immunostaining was also observed, showing a high expression in 15/31 of cases (48.4\%).

In the non-cirrhotic and non-malignant tissues, GRPR was also expressed, mostly with a weak to moderate expression $(36.4 \%$ and $59.1 \%$, respectively). It was not observed a significant difference in GRPR expression among the malignant processes and the adjacent tissues by Kruskal-Wallis analysis of variance. The Mann-Whitney test was also not able to demonstrate a statistical significant difference in the GRPR expression among neoplastic and cirrhotic or adjacent normal tissue $(\mathrm{p}=0.867)$. Figure 2 shows the overall GRPR expression in malignant and normal tissues. Though the overall analysis of variance did not show any difference between tissues, individual comparisons showed a significantly higher expression of score $3^{+}$(strong expression) in malignant tissue as well as absence of expression, $\mathrm{p}<0.05$ (Table 2).

To better understand the significance of GRPR expression in HCC, we correlated the expression level with major clinicopathologic features. GRPR expression was significantly associated with tumor stage $(\mathrm{P}=0.047)$, but no correlation was observed with other clinicopathologic parameters (age, gender, virus, liver cirrhosis, tumor size, and AFP level) $(\mathrm{P}>0.05)$ (Table 3$)$.

Table 1. Clinical description of the sample studied $(n=61)$

\begin{tabular}{|c|c|c|c|}
\hline Characteristic & $\mathbf{n}$ & $\%$ & Mean \\
\hline \multicolumn{4}{|l|}{ Sex } \\
\hline Female & 19 & 31.1 & \\
\hline Male & 42 & 68.9 & \\
\hline \multicolumn{3}{|l|}{ Age at diagnosis } & 59 (range: $14-83$ ) \\
\hline \multicolumn{4}{|l|}{$\mathrm{HCV}$} \\
\hline Absent & 23 & 61 & \\
\hline Present & 36 & 39 & \\
\hline \multicolumn{4}{|l|}{ Liver Cirrhosis } \\
\hline Absent & 20 & 32.8 & \\
\hline Present & 41 & 67.2 & \\
\hline \multicolumn{4}{|l|}{ Tumor stage } \\
\hline I & 15 & 25.4 & \\
\hline II & 11 & 28.6 & \\
\hline III & 26 & 44 & \\
\hline IV & 7 & 11.9 & \\
\hline \multicolumn{4}{|c|}{ Vascular invasion } \\
\hline Absent & 34 & 85 & \\
\hline Present & 6 & 15 & \\
\hline
\end{tabular}


Table 2. Staining intensity of GRPR expression in normal liver and HCC tissue

\begin{tabular}{|c|c|c|c|}
\hline \multirow{2}{*}{$\begin{array}{c}\text { Staining intensity } \\
\text { score }\end{array}$} & \multicolumn{2}{|c|}{ Pathological characterization } & \multirow{2}{*}{ P value } \\
\cline { 2 - 3 } & $\begin{array}{c}\text { Normal tissue (\%) } \\
\mathbf{n = 2 2}\end{array}$ & $\begin{array}{c}\text { Malignant tissue } \\
\mathbf{( \% )} \mathbf{~ n = 6 1}\end{array}$ & \\
\hline Score 0 (none) & 0 & 23 & 0.033 \\
\hline Score 1+ (weak) & 36.4 & 19.7 & 0.191 \\
\hline Score 2+ (moderate) & 59.1 & 27.9 & 0.015 \\
\hline Score 3+ (strong) & 4.5 & 29.5 & 0.041 \\
\hline
\end{tabular}
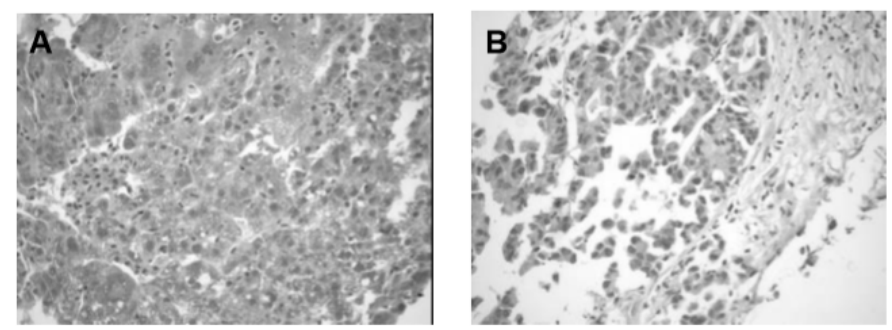

Figure 1. Antibody staining in hepatocellular carcinoma tissues. (A) GRPR immunoexpression in HCC positive strong staining x 200 and (B) weak expression

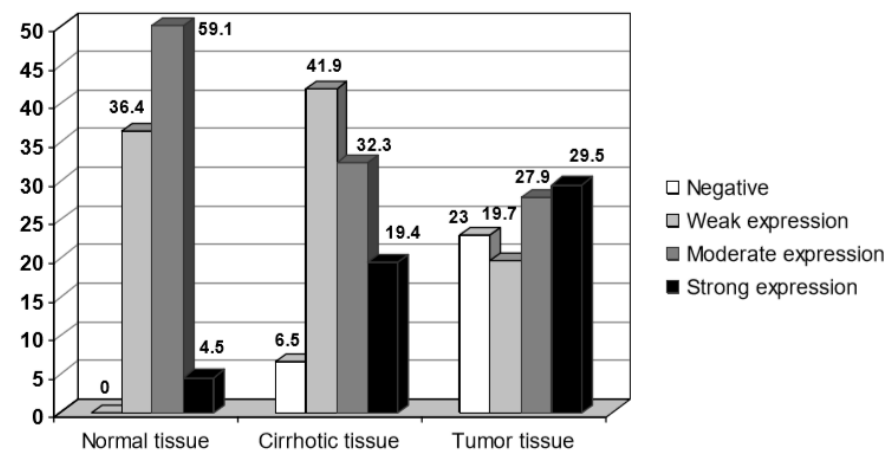

Figure 2. Overall expression of GRPR in $\mathrm{HCC}(\mathrm{n}=61)$ compared with surrounding cirrhotic tissue $(n=31)$ and normal hepatocellular tissue $(n=22), p=0.867$. Although tumor tissue expressed diffuse immunopositivity with the majority exhibiting a strong staining pattern compared with cirrhotic and normal tissue, general expression was not different among normal and neoplastic tissue $(\mathrm{p}=0.867)$

During the follow-up observation period, locoregional recurrence or distant metastases occurred in 5 of the 20 patients $(25 \%)$ that underwent procedures with curative intent (hepatectomy or transplant) and death was confirmed in $65 \%$ of patients with valid information $(33 / 51)$.

To assess the prognostic significance of GRPR expression, we analyzed overall survival (OS) and disease-free survival (DFS) rates using the Kaplan-Meier method. At the 5-year follow-up, approximately $40.3 \%$ of the patients with low GRPR expression survived, whereas $13.8 \%$ of the patients with high GRPR expression survived. Estimated mean for survival time in the group with high GRPR expression was 21.6 months, whereas in patients with low GRPR expression it was 42.6 months (Figure 3). Similarly, at the 2-year follow-up of patients submitted to hepatectomy or transplant, approximately $79.5 \%$ of the patients with low GRPR expression were disease-free, whereas $43.8 \%$ with high GRPR expression were free of relapse (Figure 4). The logrank test showed that patients who expressed higher GRPR staining tended to have a shorter overall survival time $(p=0.174)$ and disease-free survival time ( $\mathrm{p}=0.188)$, but no significant relation was found.

\section{Discussion}

This study focused on evaluating GRPR as a potential target for new molecular therapies against HCC. This is the first study looking at the GRPR expression in tissue samples obtained from patients with HCC using immunohistochemical methods. Additional samples obtained from cirrhotic and normal liver tissue from patients were used as controls.

We were able to demonstrate the presence of abundant expression of GRPRs in human hepatocellular carcinoma, while cirrhotic and normal tissues had a less pronounced receptor density, though it was also expressed. Bombesin expression in HCC was defined in primary rat liver cancers by immunohistochemical methods and was found in neurosecretory granules in $13 \%$ of the nodules and $29 \%$ of the hepatocellular carcinomas. Normal, peritumorous liver tissue, including the frequent atypical foci present in the latter two categories, was negative for this marker $[18,19]$.

The above mentioned authors suggested that des-differentiation of altered hepatocytes in a neuroendocrine direction could be a late event in liver carcinogenesis, thereby contributing to tumor formation. Our study provides a different perspective, since GRPR was also expressed in surrounding cirrhotic tissues and normal liver, though less pronounced than in neoplastic lesions.

In a previous study the treatment of peptide analogs targeted to receptors for luteinizing hormone-releasing hormone, somatostatin or BLP and their combinations strongly inhibit growth HCC in nude mice [20].

The GRP receptors in the primary carcinomas are often heterogeneously distributed. BLP play many physiological roles including the regulation of smooth muscle contraction, the release of hormones and the secretion of enzymes [5], occuring in peripheral blood cells from healthy subjects [21] and in several organs, such as breast lobules and ducts [22], the gastric antrum [23] and the pancreas [24].

In our study, we describe a ubiquitous GRPR expression in non-neoplastic liver tissue, ranging from moderate to high density

Table 3. Correlation of different clinicopathologic features with GRPR expression in HCC

\begin{tabular}{|c|c|c|c|}
\hline \multirow{2}{*}{$\begin{array}{l}\text { Clinicopathologic } \\
\text { characteristics }\end{array}$} & \multicolumn{2}{|c|}{ All Patients $(n=61)$} & \multirow[b]{2}{*}{$P$ value } \\
\hline & $\begin{array}{c}\text { GRPR low } \\
\text { expression }(n=35)\end{array}$ & $\begin{array}{c}\text { GRPR high } \\
\text { expression }(n=26)\end{array}$ & \\
\hline \multicolumn{4}{|c|}{ Age } \\
\hline$<55 \mathrm{y}$ & 11 & 9 & \\
\hline$\geq 55 y$ & 24 & 17 & 0.793 \\
\hline \multicolumn{4}{|c|}{ Gender } \\
\hline Male & 23 & 19 & \\
\hline Female & 12 & 7 & 0.539 \\
\hline \multicolumn{4}{|c|}{ HbsAG } \\
\hline Absent & 14 & 9 & \\
\hline Present & 20 & 16 & 0.687 \\
\hline \multicolumn{4}{|c|}{ Liver cirrhosis } \\
\hline Absent & 12 & 8 & \\
\hline Present & 23 & 18 & 0.772 \\
\hline \multicolumn{4}{|l|}{ Tumor stage } \\
\hline I & 5 & 10 & \\
\hline II & 5 & 6 & \\
\hline III \& IV & 23 & 10 & \\
\hline \multicolumn{4}{|c|}{ Histological grade } \\
\hline Well to moderate & 3 & 3 & \\
\hline Poor & 22 & 13 & 0.551 \\
\hline \multicolumn{4}{|c|}{ AFP level } \\
\hline$<100 \mathrm{ng} / \mathrm{ml}$ & 17 & 13 & \\
\hline$\geq 100 \mathrm{ng} / \mathrm{ml}$ & 12 & 9 & 0.973 \\
\hline \multicolumn{4}{|c|}{ Tumor size } \\
\hline$<5 \mathrm{~cm}$ & 14 & 15 & \\
\hline$\geq 5 \mathrm{~cm}$ & 20 & 11 & 0.205 \\
\hline
\end{tabular}




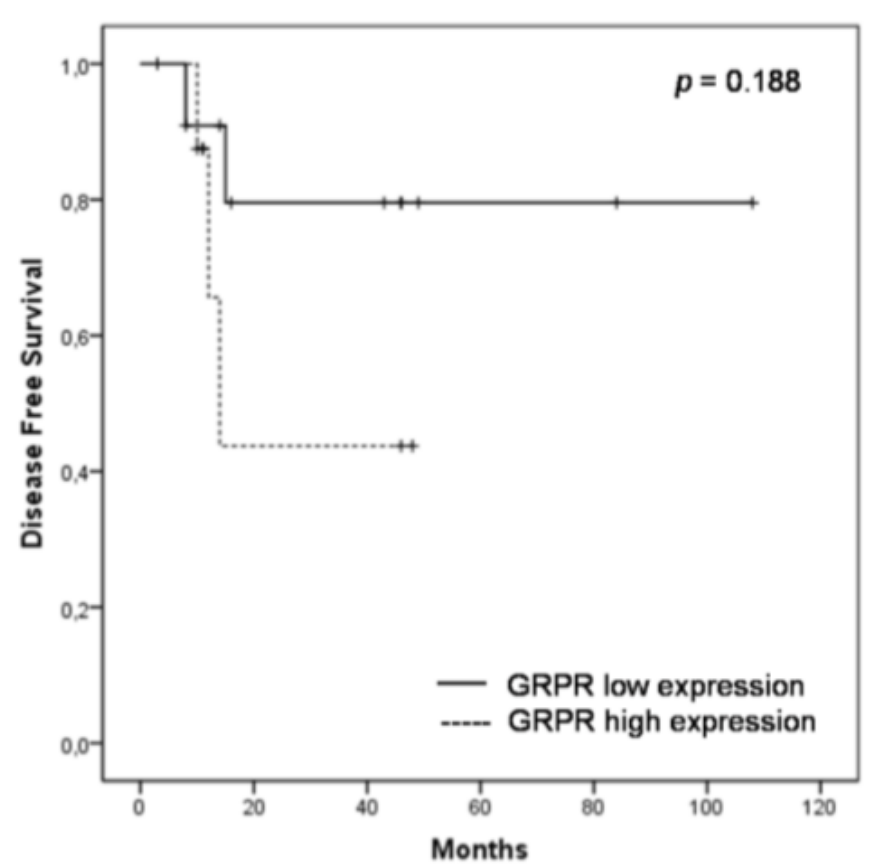

Figure 3. Kaplan-Meier curves for OS of patients with high and low GRPR expression in HCC tissue. Patients with high GRPR expression tended to have a shorter OS time $(\mathrm{p}=$ 0.174 ) compared to patients with low expression

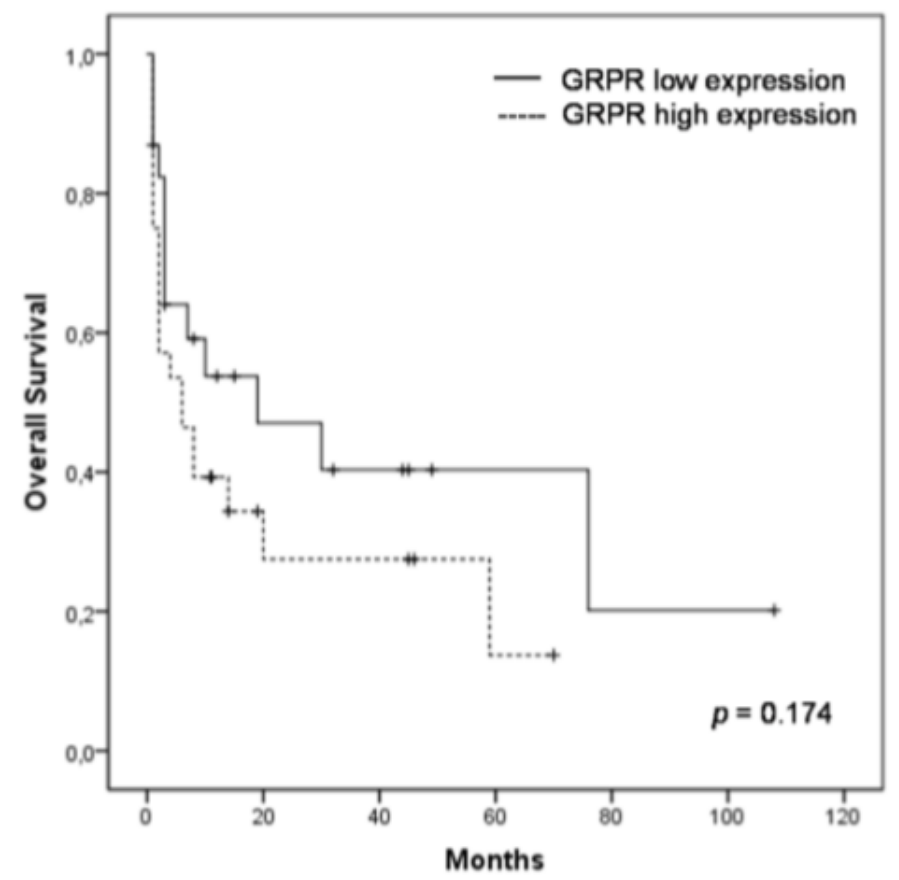

Figure 4. DFS in patients with high and low GRPR expression with no evidence of disease after surgery. Patients with high GRPR expression relapsed earlier than patients with low expression $(\mathrm{p}=0.188)$

values. The reason for such a heterogeneity in normal tissue is not clear and needs further investigations. Considering that the sample size containing non-neoplastic tissue was often small, the percentage of receptor heterogeneity may not be representative for the whole liver parenchyma. The observed heterogeneity could be related to a heterogeneous inervation pattern, assuming that GRP plays a neurotransmitter role in the liver, as it does in the other gastrointestinal organs previously evaluated.
Together with defining GRPR expression in HCC, we tried to determine the correlation between its expression and the clinical outcome in patients. In the specimens examined, GRPR expression status was mainly observed in tumors of moderate to poor differentiation, while well differentiated carcinomas lacked GRPR expression $(\mathrm{p}=0.55)$.

Furthermore, it appears to be a correlation of GRPR high expression and relapse after hepatectomy, since $57.1 \%$ of patients who relapsed were GRPR-positive, in comparison to $42.9 \%$ of those who had no evidence of disease in the follow-up. Even though it did not reach statistical significance, it could be inferred that GRPR expression might be related to the aggressiveness of the disease. Such finding has also been observed in studies with GRPR expression in prostate cancer [25], in which positive immunoexpression of GRP was clearly associated with relapse $(\mathrm{p}=0.029)$ and advanced tumor stages $(\mathrm{p}=0.049)$.

Several lines of experimental evidence have suggested that the GRP and other BLP are involved with tumor progression, enhancing angiogenesis, local invasion and distant metastases [3]. However, some series have shown that, at least in vitro, GRP/GRPR may actually improve patient outcome. It could be associated with a capacity of enhancing tumor cell attachment to the extracellular matrix [26,27], attenuating metastasis and promoting natural killer (NK) cell binding and cytolysis [28].

Considering the different possible functions suggested for GRP, many studies have assessed the role of GRPR as a prognostic factor for different types of cancer. Studies on lung and colorectal cancer showed that aberrant expression of this peptide receptor was not associated with worse clinical outcome, since patients expressing GRPR had better survival rates when compared with patients with no GRPR expression $[29,30]$.

As in other studies performed in samples obtained from patients with breast and prostate cancer [25,31], our results in HCC suggested that GRPR expression had a negative impact in overall patient survival. The expression of GRPR could correlate with patient survival or tumor recurrence even when GRP expression does not [32]. That could be due to other ligands in the bombesin family that activates the GRPR and also to the susceptibility of being constitutively active, at least when ectopically expressed in a non-malignant human cell line [33].

The observation that GRPR could act as an autocrine growth factor for several tumors have encouraged the synthesis of GRPR antagonists for the experimental treatment of different malignancies. The synthetic antagonists bind with high affinity to the receptors, blocking the signaling pathways, and have exhibited antitumor activity both in vitro and in vivo [34].

The high GRPR expression in a large spectrum of human cancers, as well as the demonstration of its role as a tumor growth factor in various tumor models gives support to the clinical evaluation of GRPR antagonists as experimental anticancer agents [3]. In various tumor types, such as prostate and cervical cancer and, more recently, gliomas, a sizeable difference between GRPR expression between neoplastic and non-neoplastic tissues could be demonstrated $[8,10,35,36]$.

Our study is the first to look at GRPR expression in tumor samples obtained from patients with HCC, as well as in tissue biopsies of cirrhotic and normal liver. GRPR was shown to be expressed in both non-malignant and malignant tissue. However, it had a high differential expression in high grade HCC as compared to normal liver tissue. We were also able to demonstrate that GRPR expression was associated with poor patient outcome. The relatively small sample size in our study limits any definitive conclusion and further studies on GRPR expression in patients with HCC are warranted. 


\section{Conflict of Interest}

The authors disclosure potentials conflict of interest.

\section{References}

1. Cuttitta F, Carney DN, Mulshine J, Moody TW, Fedorko J, et al. (1985) Bombesinlike peptides can function as autocrine growth factors in human small-cell lung cancer. Nature 316: 823-826. [Crossref]

2. Nagy A, Schally AV (2005) Targeting cytotoxic conjugates of somatostatin, luteinizing hormone-releasing hormone and bombesin to cancers expressing their receptors: a 'smarter' chemotherapy. Curr Pharm Des 11: 1167-1180.

3. Cornelio DB, Roesler R, Schwartsmann G (2007) Gastrin-releasing peptide receptor as a molecular target in experimental anticancer therapy. Ann Oncol 18: 1457-1466.

4. Costa M, Furness JB, Yanaihara N, Yanaihara C, Moody TW (1984) Distribution and projections of neurons with immunoreactivity for both gastrin-releasing peptide and bombesin in the guinea-pig small intestine. Cell Tissue Res 235: 285-293. [Crossref]

5. Bunnett N (1994) Gastrin releasing peptide; in Walsh JH, Dockray GJ (eds): Gut Peptides: Biochemistry and Physiology, New York pp. 423-445.

6. Hildebrand P, Lehmann FS, Ketterer S, Christ AD, Stingelin T, et al. (2001) Regulation of gastric function by endogenous gastrin releasing peptide in humans: studies with a specific gastrin releasing peptide receptor antagonist. Gut 49: 23-28.

7. Schally AV, Chang RC, Arimura A, Redding TW, Fishback JB, et al. (1981) High molecular weight peptide with corticotropin-releasing factor activity from porcine hypothalami. Proc Natl Acad Sci U S A 78: 5197-5201.

8. Cornelio DB, Meurer L, Roesler R, Schwartsmann G (2008) Gastrin-Releasing Peptide Receptor Expression in Cervical Cancer. Oncology 73: 340-345.

9. de Oliveira MS, Cechim G (2009) Anti-proliferative effect of the gastrinrelease peptide receptor antagonist RC-3095 plus temozolomide in experimental glioblastoma models. J Neurooncol 93: 203. [Crossref]

10. Flores GD, Meurer L, Uberti AF, Macedo BR, Lenz G, et al. (2010) Gastrin-releasing peptide receptor content in human glioma and normal brain. Brain Res Bull 82: 95-98.

11. Pereira AS, DiLeone L, Souza FH, Schwartsmann G, De Nucci G (2005) Quantification of the bombesin/gastrin releasing peptide antagonist RC3095 by liquid chromatographytandem mass spectrometry. J Chromatogr B Analyt Technol Biomed Life Sci 816: 321-326.

12. Schwartsmann G (2006) A phase I trial of the bombesin/gastrin-releasing peptide (BN/ GRP) antagonist RC3095 in patients with advanced solid malignancies. Invest New Drugs 24: 403-412.

13. Parkin DM (2001) Global cancer statistics in the year 2000. Lancet Oncol 2: 533-543. [Crossref]

14. Llovet JM, Beaugrand M (2003) Hepatocellular carcinoma: present status and future prospects. J Hepatol 38: 136-149.

15. Giovannini M, Elias D, Monges G, Raoul JL, Rougier P (2001) French National Federation of Cancer (FNCLCC) (2001) Hepatocellular carcinoma. Br J Cancer 84 Suppl 2: 74-77. [Crossref]

16. Moffat DF, Oien KA, Dickson J, Habeshaw T, McLellan DR (2000) Hepatocellular carcinoma after long-term tamoxifen therapy. Ann Oncol 11: 1195-1196. [Crossref]

17. Poon RT, Ng IO, Fan ST, Lai EC, Lo CM, et al. (2001) Clinicopathologic features of long-term survivors and disease-free survivors after resection of hepatocellular carcinoma: a study of a prospective cohort. J Clin Oncol 19: 3037-3044. [Crossref]

18. Seglen PO, Skomedal H, Saeter G, Schwarze PE, Nesland JM (1989) Neuroendocrine differentiation and bombesin production in carcinogeninduced hepatocellular rat tumours. Carcinogenesis 10: 21-25.
19. Nilsson H, Eriksson LC (1994) Growth factor induced mitogenic effects and inositol phosphate responses in primary hepatocyte cultures from normal rat liver and rat liver nodules. Carcinogenesis 15: 1821-1826.

20. Szepeshazi K, Schally AV, Treszl A, Seitz S, Halmos G (2008) Therapy of experimental hepatic cancers with cytotoxic peptide analogs targeted to receptors for luteinizing hormonereleasing hormone, somatostatin or bombesin. Anticancer Drugs 19: 349-358.

21. Shingyoji M, Takiguchi Y, Watanabe R, Hiroshima K, Motoori K, et al. (2003) Detection of tumor specific gene expression in bone marrow and peripheral blood from patients with small cell lung carcinoma. Cancer 97: 1057-1062. [Crossref]

22. Gugger M, Reubi JC (1999) Gastrin-releasing peptide receptors in non-neoplastic and neoplastic human breast. Am J Pathol 155: 2067-2076. [Crossref]

23. Ferris HA, Carroll RE, Lorimer DL, Benya RV (1997) Location and characterization of the human GRP receptor expressed by gastrointestinal epithelial cells. Peptides 18 : 663-672.

24. Xiao D, Wang J, Hampton LL, Weber HC (2001) The human gastrin-releasing peptide receptor gene structure, its tissue expression and promoter. Gene 264: 95-103.

25. Constantinides C, Lazaris AC, Haritopoulos KN, Pantazopoulos D, Chrisofos M, et al. (2001) Immunohistochemical detection of gastrin releasing peptide in patients with prostate cancer. World J Urol 21: 183-187. [Crossref]

26. Glover S, Delaney M, Dematte C, Kornberg L, Frasco M, et al. (2004) Phosphorylation of focal adhesion kinase tyrosine 397 critically mediates gastrinreleasing peptide's morphogenic properties. J Cell Physiol 199: 77-88. [Crossref]

27. Taglia L, Matusiak D, Matkowskyj KA, Benya RV (2006) Gastrinreleasing peptide mediates its morphogenic properties in human colon cancer by upregulating intracellular adhesion protein-1 (ICAM-1) via focal adhesion kinase. Am J Physiol Gastrointest Liver Physiol 292: G182-G190. [Crossref]

28. Taglia L, Matusiak D, Benya RV (2008) GRP-induced up-regulation of Hsp72 promotes CD16?/94? natural killer cell binding to colon cancer cells causing tumor cell cytolysis. Clin Exp Metastasis 25: 451-463.

29. Toi-Scott M, Jones CL, Kane MA (1996) Clinical correlates of bombesin-like peptide receptor subtype expression in human lung cancer cells. Lung Cancer 15: 341-354.

30. Carroll RE, Matkowskyj KA, Chakrabarti S, McDonald TJ, Benya RV (1999) Aberran expression of gastrin-releasing peptide and its receptor by well differentiated colon cancers in humans. Am J Physiol 276: G655-G665.

31. Chao C, Ives K, Hellmich HL, Townsend CM Jr, Hellmich MR (2009) Gastrinreleasing peptide receptor in breast cancer mediates cellular migration and interleukin-8 expression. J Sur Res 156: 26-31.

32. Rivera CA, Ahlberg NC, Taglia L, Kumar M, Blunier A, et al. (2009) Expression of GRP and its receptor is associated with improved survival in patients with colon cancer. Clin Exp Metastasis 26: 663-671. [Crossref]

33. Ferris HA, Carroll RE, Rasenick MM, Benya RV (1997) Constitutive activation of the gastrin-releasing peptide receptor expressed by the non-malignant human colon epithelial cell line NCM460. J Clin Invest 100: 2530-2537. [Crossref]

34. Moody TW, Sun LC, Mantey SA, Pradhan T, Mackey LV, et al. (2006) In vitro and in vivo antitumor effects of cytotoxic camptothecin-bombesin conjugates are mediated by specific interaction with cellular bombesin receptors. $J$ Pharmacol Exp Ther 318: 1265-1272. [Crossref]

35. Bartholdi MF, Wu JM, Pu H, Troncoso P, Eden PA, et al. (1998) In situ hybridization for gastrin-releasing peptide receptor (GRP receptor) expression in prostatic carcinoma. Int J Cancer 79: 82-90. [Crossref]

36. Markwalder R, Reubi JC (1999) Gastrin-releasing peptide receptors in the human prostate: relation to neoplastic transformation. Cancer Res 59: 1152-1159.

Copyright: $@ 2018$ Lazaretti NS. This is an open-access article distributed under the terms of the Creative Commons Attribution License, which permits unrestricted use, distribution, and reproduction in any medium, provided the original author and source are credited. 